ENTORNOS, No. 27. | Abril 2014

ARTÍCULO DE INVESTIGACIÓN

Recibido: 4 Febrero / Recibido en forma revisada: 5 Marzo / Aceptado: 12 Abril

\title{
Estudio etnobotánico para la identificación del recurso forestal no maderable con mayor potencial medicinal y comercial en la cuenca media y baja del río Las Ceibas en Neiva Colombia
}

\author{
Ethnobotanical study to identify the non timber-yielding forest \\ resource with the biggest medical and commercial potential in the \\ low and middle basin of The Ceibas river in the city of Neiva \\ Colombia
}

\author{
Ethnobotanische Forschung Für Die Identifizierung Von Hoch \\ Medizinische Und Wirtschaftliche Hilfsmittel Im Flussbett Über \\ Und Unter Dem Las Ceibas In Neiva Kolumbien
}

\author{
Sandra Vianney Fajardo \\ Magister en Ecología y Gestión de Ecosistemas Estratégicos. \\ Docente Titular Secretaría Educación de Neiva.
}

\begin{abstract}
Resumen
La cuenca del río Las Ceibas se encuentra en el municipio de Neiva al norte del departamento del Huila y es considerada un ecosistema estratégico por sus servicios ecosistémicos que presta, en especial por abastecer de agua el acueducto de la ciudad de Neiva. En ésta cuenca se presentan conflictos de uso y aprovechamiento de recursos naturales generados por presiones que ejercen sus habitantes por usos inadecuados de los recursos naturales, para obtener materias primas, alimentos y recursos económicos, conllevando a un proceso continuo de deterioro. Por estas razones, se estudiaron las especies vegetales utilizadas con fines medicinales para identificar aquella con mayor potencial medicinal y comercial para promover la gestión sostenible de la flora de la cuenca media y baja del río Las Ceibas.
\end{abstract}

Por lo anteriormente expuesto, se realizó un estudio etnobotánico entre los años 2010 y 2011 , en el cual se aplicaron técnicas de identificación y jerarquización de la flora de uso medicinal mediante el uso de una serie de criterios relacionados, que permitieron identificar la plantas con mayor potencial para establecer un proceso de sostenibilidad ambiental. Como resultado del estudio se registraron de 61 especies vegetales correspondientes a 39 familias, de las cuales ocho especies son medicinales con posibilidades de aprovechamiento sostenible, de éstas, la especie Lippia alba (Mill) N.E.Br. (Pronto Alivio) es la planta con mayor potencial medicinal y de comercialización encontrada en la cuenca media y baja del río Las Ceibas.

Palabras clave: Recurso forestal no maderable, Río Las Ceibas, Gestión de ecosistemas, Lippia alba.
Abstract

The Ceibas river basin is located in the municipality of Neiva in the north part of Huila. Due to its ecosystem services, it is a strategic ecosystem, but mainly for the water service supplied to the aqueduct of the city. In this basin there are conflicts and pressing situations generated by inappropriate uses of natural resources on the part of its inhabitants in order to get raw materials, food and economic resources which constitute a continuous process of deterioration. For these reasons plant species for medicinal purposes were studied to identify those having greater medical and commercial potential and promote sustainable management of the middle and lower basin of the Ceibas river.

For the above mentioned reasons, between 2010 and 2011 it was conducted an ethnobotanical study and identifying and prioritizing techniques were applied. These techniques combined a number of criteria which allowed to identify the plant with the greatest potential to establish a process of environmental sustainability. As a result, 61 species corresponding to 39 families were registered. From this group eight species are medicinal plants with potential for sustainable use. In accordance with the selection criteria applied to Lippia alba (Mill) N.E.Br., (Pronto Alivio) is the plant with the greatest potential found in the middle and lower basin of the Ceibas river.

Keywords: non- timber forest resource, The Ceibas river, ecosystem management, Lippia alba. 


\section{Zusammenfassung}

Das Flussbett des "Las Ceibaas" Flusses befindet sich im Landkreis Neiva, im nördlichen Teil des "Bundesstaates" Huila. Durch seine ökosistemischen Eigenschaften, wird es als ein strategisches Ökosystem bezeichnet, vor allem aber für seine Eigenschaft als Wasserlieferant für das Aquädukt der Stadt Neiva. Im Flussbett selbst gibt es Konflikte und Ärger durch unadäquate Nutzung der Naturressourcen für Gewinnung von Rohstoffen, Nahrungsmitteln und ökonomische Ressourcen durch seine Einwohner, welche zum fortlaufenden Prozess der Zerstörung beitragen. Deswegen wurden Studien zur Findung bestimmter natürlicher Heilpflanzen begonnen, um eine bestimmte Heilplflanze zu identifizieren, welche grosses medizinisches und kommerzielles Potential hat und somit als Anreiz dienen kann, nachhaltiges Management im Flussbett über und unter dem Las Ceibas Fluss zu betreiben.

\section{Introducción}

La importancia de la cuenca del río las Ceibas está en su función como abastecedora del acueducto del municipio de Neiva, categorizándose como ecosistema estratégico del departamento. Cabe agregar que el grupo ECOSURC de la Universidad Surcolombiana ha propuesto para la cuenca nueve criterios ecológicos y socioculturales para reconocer su importancia y valorarlo como un ecosistema estratégico. Entre estos criterios se tienen: asentamientos humanos, agua para el consumo humano, defensas y amenazas naturales, actividades educativas y científicas, diversidad natural, reconocimiento legal y académico, agua y suelo para la agricultura, vías de comunicación y telecomunicaciones (Olaya y Sánchez, 2003; Patiño, 2004).

También existen otros criterios que la valoran por su grado de vulnerabilidad en cuanto a la inestabilidad del terreno e inundaciones en épocas de lluvias, límites naturales, área de influencia, control geopolítico y militar, y el agua y suelos para la agricultura y ganadería deteriorando la calidad del agua (Olaya, 2003). El problema de la pérdida de la cobertura boscosa se encuentra asociado al incremento de actividades productivas como: la ganadería, la agricultura y las prácticas inapropiadas de explotación agropecuaria como las quemas; actividades que históricamente han realizado los habitantes de la cuenca.

El Plan de Ordenación y Manejo de la Cuenca Hidrográfica del río Las Ceibas desarrollado por la CAM (2006), propone la necesidad de identificar el recurso forestal no maderable, como una de los aspectos necesarios para fomentar el desarrollo sustentable de los recursos naturales renovables allí presentes. En éste sentido, Martínez (2006) argumenta la importancia de presentar alternativas de desarrollo rural para las comunidades presentes de estos ecosistemas estratégicos, que orienten la gestión del ecosistema hacia la conformación de una estructura de mercado sostenible de sus recursos naturales; entre los cuales el recurso forestal no maderable puede tener un papel importante.

Este desarrollo sustentable es posible en la medida que los recursos forestales no maderables tengan valor comercial en sus funciones como generadores de alimentos para el hombre y animales, fármacos y generación de empleo. Sin embargo, la mayoría de estos productos van dirigidos al autoconsumo y a la venta informal, por lo cual no se cuantifica en las ganancias nacionales, reduciendo su importancia dentro de la economía colombiana (Puelles, 2008).

Martínez (2005) atribuye la importancia del valor comercial de las especies vegetales como fuente de obtención de materias primas para productos farmacéuticos y aromáticos; además expone que la demanda en los mercados internacionales de éstas materias primas ha aumentado de manera considerable y que este fenómeno ha causado vulnerabilidad en los recursos biológicos y en las culturas regionales por la falta de métodos de recolección sustentable y amigable con el ecosistema. En Colombia la comercialización y uso de las plantas medicinales está vigilada por Instituto Nacional de Vigilancia de Medicamentos y Alimentos, que se rige mediante el decreto 3553 de 2004, mediante el cual reglamenta los registros sanitarios y los regímenes de vigilancia, control sanitario y publicidad de los productos fitoterapéuticos, para esto ha publicado el Vademécum Colombiano de Plantas Medicinales (Colombia. Ministerio de la Protección Social, 2004a).

El enfoque por ecosistemas, se fundamenta en la aplicación de metodologías científicas adaptadas al entorno, enfocadas al manejo de la diversidad biológica y de las funciones e interacciones entre individuos y su medio ambiente. Este enfoque establece que el ser humano hace parte integral de la diversidad ecosistémica; de este modo, se convierte en una estrategia importante para la gestión integrada de los recursos naturales, permitiendo promover la conservación y el uso sustentable de manera equitativa. En Colombia la anterior situación es más evidente en las áreas protegidas de carácter regional, en donde, la implementación de proyectos de gestión requiere de procesos adaptables y eficientes que respondan al mantenimiento equilibrado de la dinámica de los ecosistemas (Convenio Sobre la Diversidad Biológica, 2007), (Secretaría del Convenio Sobre la Diversidad Biológica, 2004).

También se ha planteado que para mantener la dinámica de las poblaciones y la interacción entre los 
factores físico-químicos presentes en los ecosistemas, es esencial orientar la gestión, la política y la planeación hacia un nuevo concepto de desarrollo agrícola e industrial, que permita utilizar la tecnología para minimizar las presiones antrópicas, mejorar las condiciones socio-económicas y garantizar las necesidades de las generaciones presentes y futuras, éste sería el desarrollo sostenible; concebido como el conjunto de oportunidades de desarrollo económico equitativo compatibles ambientalmente para el equilibrio de los ecosistemas (Mejías, 2002), (Kammerbauer, 2001), (Vega, 2001).

En el año 1993 Colombia formalizó el concepto de desarrollo sostenible con la expedición de la Ley 99 de 1993, entendido como los procesos que conducen al crecimiento económico, mejorar la calidad de vida y el bienestar social sin perjudicar el medio ambiente y sin menoscabar las posibilidades de las generaciones futuras (Colombia. Congreso de la República de Colombia, 1993)

Dentro de los procesos de desarrollo sostenible se ha reconocido que los productos forestales no maderables, constituyen elementos importantes en los programas de gestión y manejo en los bosques tropicales, como un mecanismo para el uso sostenible de la biodiversidad (López et al., 2006); estos mismos autores señalan que las investigaciones en recursos no maderables del bosque deben incluir fases de identificación, conocimiento en cuanto al uso que se hace, la oferta y su posible comercialización.

En éste sentido los bosques existentes en la Cuenca Hidrográfica del río Las Ceibas, cuentan con gran diversidad de semillas, cortezas, flores, frutos, raíces y hojas como potencial productivo generador de materias primas para la producción de aceites esenciales, gomas, resimas, pigmentos, tintes naturales y medicinales (Corporación Autónoma Regional del Alto Magdalena, 2006); recursos que permitirían desarrollar procesos comunitarios sustentables.

Vega (2001) sostiene que el incipiente conocimiento científico que convalide la riqueza y el potencial de los recursos forestales no maderables, se constituye en un obstáculo para desarrollar propuestas sustentables basadas en los recursos biológicos. En consecuencia, investigaciones puntuales que generen información orientada al aprovechamiento de los recursos forestales no maderables del bosque pueden contribuir de manera significativa a la propuesta de gestión de la cuenca media y baja del río Las Ceibas. En este orden de ideas se plantearon las siguientes preguntas de investigación: De la diversidad forestal no maderable existente ¿Cuáles son las especies silvestres utilizadas como medicinales por la comunidad? y de estas ¿cuál tiene mayor uso y potencial comercial?

\section{Metodología}

\section{Área de estudio}

La Cuenca Hidrográfica del Río Las Ceibas, se localiza en el costado oriental de la ciudad de Neiva, sobre la vertiente occidental de la cordillera oriental, delimitada por accidentes geográficos muy definidos, que van desde las altas montañas, que dividen al municipio con el departamento del Caquetá, hasta la desembocadura del río Magdalena, en un área aproximada de 30,128 Ha aproximadamente (Figura 1 ).

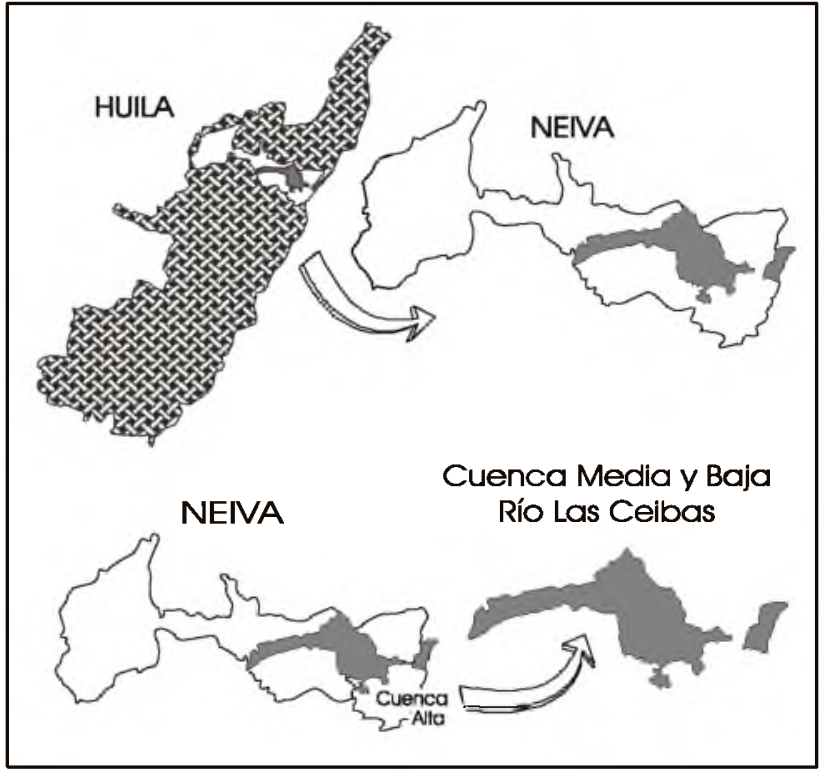

Figura 1. Área de estudio, Cuenca media y baja del río Las Ceibas

Las elevaciones mínimas y máximas corresponden respectivamente a los 430 metros de altura en la desembocadura en el río Magdalena, y 2.600 metros de altura, en la divisoria de la cordillera oriental (Olaya, 2005). El área de estudio etnobotánico comprende la zona media y baja de la cuenca que corresponde a las veredas: San Miguel, Canoas, Primavera, Palestina, Santa Lucía, Santa Helena, El Vergel, Cauchos, Floragaita, Santa Bárbara, Platanillal, Ceibas Afuera, El Centro y Venadito, con una población aproximada de 1200 habitantes (Corporación Autónoma Regional del Alto Magdalena, 2006).

La investigación realizada entre los años 2010 y 2011 contemplo dos fases: La fase uno identificó y realizó un reconocimiento del recurso forestal no maderable con fines medicinales; en la fase dos se seleccionó el recurso forestal no maderable con mayor potencial para el aprovechamiento sostenible.

\section{Estudio Etnobotánico}

Para realizar la caracterización etnobotánica se realizó una valoración socio-económica del recurso forestal no maderable, según la metodología propuesta por Galeano (2000), que consiste en indagar mediante encuestas y entrevistas sobre los usos y hábitat de las 
plantas medicinales. Estas encuestas y entrevistas fueron dirigidas a los habitantes de la cuenca media y baja del río Las Ceibas, a los comerciantes de los principales mercados de plantas medicinales presentes en la ciudad de Neiva y a los profesionales que están involucrados en la ejecución del plan de manejo de la cuenca.

Para seleccionar la población objeto de las encuestas, se aplicó la siguiente formula (Kuehl, 2001):

$\mathrm{n}=\mathrm{N} \times \mathrm{Z}^{2} \times \mathrm{q} \times \mathrm{p}$

$d^{2} \times(N-1)+Z^{2} \times p \times q$

Es así que,

$\mathrm{N}=$ tamaño de la población que para el caso es 361 núcleos familiares.

$\mathrm{Z}=$ el nivel de confianza que para el $95 \%$ es de 1.96

$\mathbf{p}=$ la probabilidad de éxito o proporción esperada. $(50 \%=0,5)$

$q=$ la probabilidad de fracaso $(1-p$ es decir $1-0,5=0,5)$

$\mathrm{d}=$ precisión o el error máximo admisible en términos de proporción fue del $10 \%$.

Como referencia para el muestreo se tomaron los 361 núcleos familiares que habitan la cuenca media y baja del río Las Ceibas según la CAM (2006). De esta manera se obtuvo una población objeto de estudio de 76 núcleos familiares.

Los entrevistados eran funcionarios del Organización de las Naciones Unidas para la Alimentación y la Agricultura (FAO), quienes integraban el equipo de profesionales que ejecutan el plan de manejo ambiental de la cuenca del río Las Ceiba, así como también a los comerciantes de plantas medicinales en la ciudad de Neiva.

\section{Identificación taxonómica}

Las plantas señaladas por los habitantes en el estudio etnobotánico fueron objeto de un proceso de identificación taxonómica. En consecuencia, estas las plantas fueron recolectadas en la cuenca media y baja del río Las Ceibas, luego se prensaron y se secaron en un horno eléctrico MLW de secado, perteneciente al laboratorio de biología de la Universidad Surcolombiana durante 24 horas a $70^{\circ} \mathrm{C}$ temperatura.

Luego se procedió a realizar la identificación mediante el empleo de las claves taxonómicas de: Maya y Agudelo (2010), Esquivel (2009), López et al. (2006), Martínez (2005), Sanso et al. (2005), Romero et al. (2002), Silva y Salimena (2002), Esquivel (1992) y con las colecciones en línea de los herbarios e instituciones como: el Herbario Forestal Universidad Distrital Bogotá UDBC, El Herbario Nacional Colombiano (COL) del Instituto de Ciencias Naturales de la Universidad Nacional de Colombia, Sistema de Información sobre Biodiversidad de Colombia. Posteriormente se corroboró la identificación con las colecciones de los Herbarios de la Universidad Surcolombiana y de la Universidad del Tolima, con este fin se sistematizo el número de colección con que fue comparada la muestra.

\section{Selección de la planta con mayor potencial medicinal y comercial}

Las plantas identificadas por los habitantes en el estudio etnobotánico, fueron sometidas a un proceso de selección que permitió escoger la planta objeto de la propuesta para el aprovechamiento sostenible del recurso forestal no maderable. Para esto se aplicó una serie de criterios que debe cumplir la planta según las metodologías propuestas por Cavero et al. (2011), Pérez (1994), CAM (2006), Martínez (2006), MarínCorba et al. (2005) y Force et al. (1995); estos criterios se detallan a continuación.

Selección de especies nativas: Para la gestión basada en el aprovechamiento de los recursos forestales no maderables es necesario propender por la conservación de la biodiversidad propia del ecosistema. Por ésta razón, el primer criterio de selección es que las especies vegetales sean nativas y para su aplicación se tuvo en cuenta los documentos y herbarios empleados para la identificación taxonómica.

Plantas medicinales oficialmente aceptadas en Colombia: Es importante resaltar que en Colombia, las plantas medicinales que pueden ser incluidas en una estructura de mercado, deben estar registradas ante el Instituto Nacional de Vigilancia de Medicamentos y Alimentos (INVIMA), las plantas que no se encuentren dentro del vademécum no se permite su uso con fines medicinales en Colombia (Colombia. Ministerio de la Protección Social, 2004b). Es así, que luego de identificar las plantas nativas de la cuenca se seleccionaron entre estas, aquellas que estén registradas en el vademécum de plantas medicinales.

Frecuencia de citación: Es la cantidad de veces que una planta es citada en las encuestas por los habitantes de la cuenca media y baja del río Las Ceibas. Entre más veces fue citada la planta representa mayor importancia para los habitantes de la cuenca media y baja del río Las Ceibas, obteniendo así mayor importancia para este criterio (Cavero et al., 2011). En consecuencia de las plantas que están aprobadas por el INVIMA, se identificaron aquellas que son más representativas para los habitantes de la cuenca media y baja del río Las Ceibas según su frecuencia de citación.

Sumatoria de Usos: Se entiende por sumatoria de usos, la variedad de enfermedades y tratamientos en los cuales se emplea la planta. Entre más usos tenga la planta mencionada tiene mayor potencial para un aprovechamiento sostenible, y de manera consecuente tendrá mayor importancia en la aplicación de este criterio. Caso contrario, la planta que tenga pocos usos tendrá menos importancia. Para este criterio se tuvo en cuenta los usos reportados por los habitantes de la 
cuenca media y baja del río Las Ceibas y los usos reportados en la bibliografía (Marín-Corba et al., 2005). Para aplicar éste criterio fue necesario realizar consulta bibliográfica para rectificar, confirmar y complementar los usos descritos por la población de la cuenca.

Valor de uso: El valor de uso es un método ampliamente usado y evalúa la importancia del uso que se hace de la planta (Cavero et al., 2011; MarínCorba et al., 2005). Se constituye en un indicador de la demanda que hay sobre el recurso natural, y también de la posible presión que hay sobre el mismo. Este criterio surge del cociente entre la frecuencia de citación y la cantidad de usos de la planta. En consecuencia, la planta que tenga mayor valor uso indica una mayor demanda por parte de los habitantes y una mayor posibilidad de ser implementada en un sistema de aprovechamiento sostenible.

Demanda comercial: La demanda comercial se refiere a la cantidad de producto que necesita el mercado, y que la cadena productiva del sector de las plantas medicinales está dispuesta a pagar. Este criterio es esencial para la gestión y el aprovechamiento sostenible de un recurso forestal no maderable, puesto que implica un posible respaldo de poder adquisitivo. Además la sostenibilidad financiera es clave para lograr sistemas de producción sostenibles; en este sentido, Gómez (2008) sostiene que son muchas las iniciativas de producción sostenible que han fracasado por falta de mercados.

Las plantas que presentaron más demanda comercial obtuvieron mayor peso en este criterio. Se manejaron cuatro categorías; producto de demanda alta a la cual se asignó peso de 5 , producto de mediana demanda al cual se dio un peso de 3 , producto de demanda baja con un peso asignado de 1 . Las plantas que no tengan demanda comercial se les asigno un peso de 0 y fueron descartadas al imposibilitar el ingreso a un sistema de comercialización. Para determinar este criterio se tuvo en cuenta documentos y datos oficiales que caracterizan el mercado colombiano de plantas medicinales, la farmacéutica y medicamentos en Colombia (Departamento Nacional de Planeación, 2003), el estudio de oferta y demanda del sector de productos naturales (PROEXPORT, 2003) y a nivel local las entrevistas realizadas en los centros de comercio de plantas medicinales de la ciudad de Neiva y se complementó con el estudio de la demanda de plantas medicinales en los municipio de Neiva y Palermo realizado por la Universidad Nacional Abierta y a Distancia UNAD (Perafan, 2009) y las entrevistas a los comerciantes de los principales mercados de plantas medicinales presentes en la ciudad de Neiva.

\section{Resultados y discusión}

\section{Estudio etnobotánico}

A continuación se presenta la información generada a partir del estudio etnobotánico aplicado en las 76 unidades familiares seleccionadas en la cuenca media y baja del río Las Ceibas. Las plantas identificadas corresponden a 61 especies entre introducidas, naturalizadas y nativas de la zona (ver cuadro 1); pertenecientes a 39 familias, de las cuales las más representativas fueron Asteraceae con 9 especies y Lamiaceae con 7 especies (Gráfica 1).

En el estudio etnobotánico se registró la Ruchica y el Árnica, pero estas dos plantas, aunque son usadas con frecuencia por los habitantes de la cuenca media y baja del río Las ceibas, son propias de la cuenca alta.

Cuadro 1. Información etnobotánica de las especies vegetales con fines medicinales de la cuenca media y baja del río las ceibas

\begin{tabular}{|c|c|c|c|c|c|c|c|}
\hline Nombre Científico & Familia & $\begin{array}{l}\text { Nombre } \\
\text { Común }\end{array}$ & Origen & $\begin{array}{l}\text { Parte de } \\
\text { la Planta } \\
\text { utilizada }\end{array}$ & $\begin{array}{l}\text { Preparación } \\
\text { y modo de } \\
\text { administración }\end{array}$ & $\begin{array}{l}\text { Uso terapéutico } \\
\text { reportado por } \\
\text { los habitantes } \\
\text { de la cuenca }\end{array}$ & $\begin{array}{l}\text { Número de } \\
\text { Colección } \\
\text { Herbario UT }\end{array}$ \\
\hline Aloe vera $\mathrm{L}$. Burman $\mathrm{f}$. & Liiiaceae & Sábila & Introducida & Penca & $\begin{array}{l}\text { Jarabe, oral; } \\
\text { emplasto, } \\
\text { uso externo }\end{array}$ & $\begin{array}{l}\text { Quemaduras, } \\
\text { tos }\end{array}$ & $\begin{array}{l}\text { Confirmado } \\
\text { por expertos }\end{array}$ \\
\hline $\begin{array}{l}\text { Alternanthera mexicana } \\
\text { Schlechtendai. }\end{array}$ & Amaranthaceae & Descanses & Introducida & $\begin{array}{l}\text { Toda la } \\
\text { planta }\end{array}$ & $\begin{array}{l}\text { Compresa, } \\
\text { uso externo }\end{array}$ & Golpes & $\begin{array}{l}000404 \text { Atiilio } \\
\text { Maza (29) }\end{array}$ \\
\hline Ambrosia cumanensis H.B.K. & Asteraceae & Altamisa & Naturalizada & Raiz & $\begin{array}{l}\text { cocimiento, } \\
\text { uso interno }\end{array}$ & Riñones & $\begin{array}{l}005040 \mathrm{H} . \\
\text { Esquivel (1996) }\end{array}$ \\
\hline Annona squamosa $\mathrm{L}$. & Annonaceae & Anón & Nativa & $\begin{array}{l}\text { Toda la } \\
\text { planta }\end{array}$ & $\begin{array}{l}\text { Cocimiento, } \\
\text { uso interno }\end{array}$ & $\begin{array}{l}\text { Ulcera, } \\
\text { diabetes }\end{array}$ & $\begin{array}{l}\text { O009399 Tatiana } \\
\text { Sanchez (17) }\end{array}$ \\
\hline Apium graveolens L. & Umbeliferae & Apio & Introducida & Hoja & Cocimiento, oral & $\begin{array}{l}\text { Dolor de } \\
\text { estomago }\end{array}$ & $\begin{array}{l}000460 \text { Armando } \\
\text { Rodriguez (26) }\end{array}$ \\
\hline Arnica montana L. & Asteraceae & Árnica & Introducida & Tallo, hoja & $\begin{array}{l}\text { Compresa, } \\
\text { uso externo }\end{array}$ & Golpes, heridas & $\begin{array}{l}\text { Confirmado } \\
\text { por expertos }\end{array}$ \\
\hline Artemisia absinthium L. & Asteraceae & Ajenjo & Introducida & Tallo, hoja & Cocimiento, oral & Indegestión & $\begin{array}{l}\text { Confirmado } \\
\text { Dor expertos }\end{array}$ \\
\hline Astronium graveolens Jacq. & Anacardiaceae & Diomate & Nativa & $\begin{array}{l}\text { hojas, } \\
\text { corteza }\end{array}$ & $\begin{array}{l}\text { Inhalación, } \\
\text { uso Interno }\end{array}$ & $\begin{array}{l}\text { Afecciones del } \\
\text { pecho y fiebre }\end{array}$ & $\begin{array}{l}009213 \text { Díaz } \\
\text { L. (6) }\end{array}$ \\
\hline
\end{tabular}




\begin{tabular}{|c|c|c|c|c|c|c|c|}
\hline Nombre Científico & Familia & $\begin{array}{l}\text { Nombre } \\
\text { Común }\end{array}$ & Origen & $\begin{array}{l}\text { Parte de } \\
\text { la Planta } \\
\text { utilizada }\end{array}$ & $\begin{array}{l}\text { Preparación } \\
\text { y modo de } \\
\text { administración }\end{array}$ & $\begin{array}{l}\text { Uso terapéutico } \\
\text { reportado por } \\
\text { los habitantes } \\
\text { de la cuenca }\end{array}$ & $\begin{array}{l}\text { Nómero de } \\
\text { Colección } \\
\text { Herbario UT }\end{array}$ \\
\hline $\begin{array}{l}\text { Austroeupatorium inulaefollum } \\
\text { H.B.K. }\end{array}$ & Asteraceae & Salvia amarga & Nativa & Hoja & $\begin{array}{l}\text { Cocimiento, } \\
\text { uso interno }\end{array}$ & Riñones & $\begin{array}{l}002089 \text { R. } \\
\text { Echeverv (2331) }\end{array}$ \\
\hline Bidens pilosa L. & Asteraceae & $\begin{array}{l}\text { Chipaca } \\
\text { Pacunga }\end{array}$ & Nativa & $\begin{array}{l}\text { Toda la } \\
\text { planta }\end{array}$ & Jarabe, oral & $\begin{array}{l}\text { Fiebres, } \\
\text { diabetes y } \\
\text { dolor en las } \\
\text { articulaciones }\end{array}$ & $\begin{array}{l}6465 \mathrm{H} . \\
\text { Esqui } 2423\end{array}$ \\
\hline Bixa orellana $L$. & Bixaceae & Achiote & Nativa & $\begin{array}{l}\text { hoja; } \\
\text { semillas }\end{array}$ & $\begin{array}{l}\text { Jarabe, oral; } \\
\text { cataplasma, } \\
\text { uso externo }\end{array}$ & $\begin{array}{l}\text { Problemas } \\
\text { respiratorios y } \\
\text { purgante }\end{array}$ & $\begin{array}{l}002142 \text { Myriam } \\
\text { Anduqula (33) }\end{array}$ \\
\hline Byrsonima crassifolia (L.)HBK. & Malpighiaceae & Encenillo & Nativa & Tallo & $\begin{array}{l}\text { Cocimiento, } \\
\text { uso Interno }\end{array}$ & $\begin{array}{l}\text { Alivia la } \\
\text { amigdalitis }\end{array}$ & $\begin{array}{l}\text { Confirmado } \\
\text { por expertos }\end{array}$ \\
\hline Calendula officinalis L. & Asteraceae & Calendula & Introducida & $\begin{array}{l}\text { Flores, tallo, } \\
\text { hojas }\end{array}$ & Cocimiento, oral & Desinflamar & $\begin{array}{l}001257 \text { Enrique } \\
\text { Quijano (21) }\end{array}$ \\
\hline Cecropia peltata L. & Cecroplaceae & Yarumo & Nativa & Hoja & $\begin{array}{l}\text { Infusión, } \\
\text { uso Interno }\end{array}$ & $\begin{array}{l}\text { Antiasmático y } \\
\text { purgante en } \\
\text { los niños }\end{array}$ & $\begin{array}{l}005952 \mathrm{H} . \\
\text { Esquivel y G. } \\
\text { de Millán ( } 86 \text { ) }\end{array}$ \\
\hline Cissus sp. & Vitaceae & $\begin{array}{l}\text { Bejuco de } \\
\text { Agraz }\end{array}$ & Nativa & Tallo & Infusión, oral & Fiebre & $\begin{array}{l}\text { 005371. H.E. } \\
\text { Esquivel } 1754\end{array}$ \\
\hline $\begin{array}{l}\text { Cordia alliodora } \\
\text { (Ruiz y Pav.) Oken. }\end{array}$ & Boraginaceae & Nogal cafetero & Nativa & Tallo & $\begin{array}{l}\text { Cataplasma, } \\
\text { cocimiento; } \\
\text { uso externo }\end{array}$ & Hernias & $\begin{array}{l}000665 \text { Raul } \\
\text { Echeverry }(654)\end{array}$ \\
\hline Costus sp. & Costaceae & Cañagrla & Nativa & Tallo & $\begin{array}{l}\text { Cocimiento, } \\
\text { uso Interno }\end{array}$ & Fiebre y vomito & $\begin{array}{l}8155 \text { Manuel } \\
\text { Vargas (63) }\end{array}$ \\
\hline Croton gossypilfolius Vahl. & Euphorbiaceae & Sangregao & Nativa & Tallo & $\begin{array}{l}\text { Topico, uso } \\
\text { Interno y externo }\end{array}$ & $\begin{array}{l}\text { Ulceras y } \\
\text { cicatrizante }\end{array}$ & $\begin{array}{l}000066 \text { Gabriel } \\
\text { Melo Orozco (13) }\end{array}$ \\
\hline Cupressus sp. & Cupresáceas & Pino cipres & Introducida & Hoja & $\begin{array}{l}\text { Cocimiento, } \\
\text { uso Interno }\end{array}$ & Gripe & $\begin{array}{l}\text { O09501 Antonio } \\
\text { Guzman (20) }\end{array}$ \\
\hline Curatella americana $L$. & Dileniaceae & Chaparro & Nativa & $\begin{array}{l}\text { cascara } \\
\text { del tallo; } \\
\text { maceraclón }\end{array}$ & $\begin{array}{l}\text { Jarabe, } \\
\text { uso interno }\end{array}$ & $\begin{array}{l}\text { Granos y otros } \\
\text { problemas de } \\
\text { la piel }\end{array}$ & $\begin{array}{l}003042 \text { José } \\
\text { Urlel Juanias(28) }\end{array}$ \\
\hline $\begin{array}{l}\text { Cymbopogon citratus } \\
\text { (D.C. ex Nees). }\end{array}$ & Poaceae & Limonclllo & Introducida & $\begin{array}{l}\text { Toda la } \\
\text { planta }\end{array}$ & Infusión, oral & $\begin{array}{l}\text { Inflamación del } \\
\text { estomago }\end{array}$ & $\begin{array}{l}006384 \text { M. } \\
\text { Acostas y A. Rojas }\end{array}$ \\
\hline Eryngium foetidum $\mathrm{L}$. & Umbeliflorae & $\begin{array}{l}\text { Cilantro } \\
\text { Cimarrón }\end{array}$ & Nativa & Hojas & $\begin{array}{l}\text { Infusión, oral; } \\
\text { catplasma, } \\
\text { uso externo }\end{array}$ & $\begin{array}{l}\text { Acidez del } \\
\text { estomago y } \\
\text { baja la fiebre }\end{array}$ & $\begin{array}{l}005530 \mathrm{R} . \\
\text { Echeverry (3938) }\end{array}$ \\
\hline Erythroxylum coca Lam. & Erythoxylaceae & Coca & Nativa & Hojas & Cataplasma & $\begin{array}{l}\text { Dolor de } \\
\text { cabeza }\end{array}$ & $\begin{array}{l}008334 \text { Tirso } \\
\text { Medina (1338) }\end{array}$ \\
\hline Euphorbia Hypericifolia L. & Euphorbiaceae & Canchalagua & Introducida & $\begin{array}{l}\text { Toda la } \\
\text { planta }\end{array}$ & $\begin{array}{l}\text { Infusión, } \\
\text { uso Interno }\end{array}$ & $\begin{array}{l}\text { Riñones, } \\
\text { purificar la } \\
\text { sangre, higado }\end{array}$ & $\begin{array}{l}007089 \text { Derly } \\
\text { Torres y Sandra } \\
\text { Rojas ( } 8 \text { ) }\end{array}$ \\
\hline Ficus carica L. & Moraceae & Brevo & Introducida & $\begin{array}{l}\text { Toda la } \\
\text { planta }\end{array}$ & $\begin{array}{l}\text { cocimiento, } \\
\text { uso externo }\end{array}$ & Fiebre & $\begin{array}{l}003234 \text { Marina } \\
\text { Rivera (42) }\end{array}$ \\
\hline $\begin{array}{l}\text { Gliricidia sepium } \\
\text { (Jacq) Steud. }\end{array}$ & Fabaceae & Matarratón & Nativa & $\begin{array}{l}\text { Hoja; } \\
\text { corteza }\end{array}$ & $\begin{array}{l}\text { Infusión } \\
\text { emplasto, } \\
\text { uso externo }\end{array}$ & $\begin{array}{l}\text { Para tratar } \\
\text { granos, } \\
\text { erisipelas y } \\
\text { varicela. }\end{array}$ & $\begin{array}{l}\text { 000871 José } \\
\text { Rafael Dlaz (7) }\end{array}$ \\
\hline Guazuma u/mifolia L. & Sterculiaceae & Guáclmo & Nativa & Tallo & Macerada & $\begin{array}{l}\text { Anti- } \\
\text { inflamatorio y } \\
\text { malestar del } \\
\text { estomago }\end{array}$ & $\begin{array}{l}\text { 002423 R. } \\
\text { Echeverry } \\
(2840)\end{array}$ \\
\hline Hibiscus rosas-sinensis L. & Malvaceae & Gólgota & Introducida & Hoja & Jarabe, oral & Gastritis & $\begin{array}{l}009195 \text { Laura } \\
\text { Ortegón (15) }\end{array}$ \\
\hline Jacaranda caucana Pittier. & Bignoniaceae & Gualanday & Nativa & $\begin{array}{l}\text { Corteza; } \\
\text { hoja }\end{array}$ & $\begin{array}{l}\text { Extracto, } \\
\text { uso Interno; } \\
\text { Cocimiento, } \\
\text { uso externo }\end{array}$ & $\begin{array}{l}\text { Purificar } \\
\text { la sangre }\end{array}$ & $\begin{array}{l}000705 \text { Luis } \\
\text { Orcasitas (100) }\end{array}$ \\
\hline Lippia alba (Mili.) N.E.Br. & Verbenaceae & Prontoalivio & Nativa & $\begin{array}{l}\text { Tallos, } \\
\text { flores; hojas }\end{array}$ & $\begin{array}{l}\text { Jarabe. Oral; } \\
\text { comprensas }\end{array}$ & $\begin{array}{l}\text { Para la } \\
\text { diabétes, gripa } \\
\text { y cicatrizante. }\end{array}$ & $\begin{array}{l}009353 \\
\text { Carolina } \\
\text { García (1) }\end{array}$ \\
\hline Lippia citriodora H.B.K. & Verbenaceae & Cldron & Introducida & $\begin{array}{l}\text { Toda la } \\
\text { planta }\end{array}$ & $\begin{array}{l}\text { cocimiento, oral; } \\
\text { cataplasta, } \\
\text { uso interno }\end{array}$ & $\begin{array}{l}\text { Indigestión, } \\
\text { náuseas y } \\
\text { problemas del } \\
\text { corazón }\end{array}$ & $\begin{array}{l}\text { Confirmado } \\
\text { por expertos }\end{array}$ \\
\hline
\end{tabular}




\begin{tabular}{|c|c|c|c|c|c|c|c|}
\hline Nombre Científico & Familia & $\begin{array}{l}\text { Nombre } \\
\text { Común }\end{array}$ & Origen & $\begin{array}{l}\text { Parte de } \\
\text { la Planta } \\
\text { utilizada }\end{array}$ & $\begin{array}{l}\text { Preparación } \\
\text { y modo de } \\
\text { administración }\end{array}$ & $\begin{array}{l}\text { Uso terapéutico } \\
\text { reportado por } \\
\text { los habitantes } \\
\text { de la cuenca }\end{array}$ & $\begin{array}{l}\text { Nómero de } \\
\text { Colección } \\
\text { Herbario UT }\end{array}$ \\
\hline Mammea americana Linn. & Guittiferae & Mamey & Nativo & Fruto & $\begin{array}{l}\text { Cocimiento, } \\
\text { uso externo }\end{array}$ & $\begin{array}{l}\text { Golpes, } \\
\text { dolores }\end{array}$ & $\begin{array}{l}008677 \text { ل. } \\
\text { Jimenez (11) }\end{array}$ \\
\hline Mandevilla sp. & Apocynaceae & Bejuco de Tos & Nativo & $\begin{array}{l}\text { Tallo, } \\
\text { hoja y flor }\end{array}$ & $\begin{array}{l}\text { cocimiento, } \\
\text { uso interno }\end{array}$ & Tos & $\begin{array}{l}002087 \text { R. } \\
\text { Echeverry R. } \\
\text { Jaramillo (329) }\end{array}$ \\
\hline Mangifera indica L. & Anacardiaceae & Mango & Introducida & Hoja & $\begin{array}{l}\text { Cocimiento, } \\
\text { uso Interno }\end{array}$ & Rînones & $\begin{array}{l}005874 \mathrm{H} \text {. } \\
\text { Esquivel y } \mathrm{G} . \mathrm{de} \\
\text { Millan(224) }\end{array}$ \\
\hline Matricaria recutita $\mathrm{L}$. & Asteraceae & Manzanilla & Introducida & Flor & Infusión & Nervios & $\begin{array}{l}\text { Confirmado } \\
\text { por expertos }\end{array}$ \\
\hline Melissa officinalis L. & Lamiaceae & Toronjil & introducido & Hojas & Infusión & $\begin{array}{l}\text { Nervios, } \\
\text { tensión }\end{array}$ & $\begin{array}{l}007515 \text { Johan } \\
\text { Carmona(3) }\end{array}$ \\
\hline $\begin{array}{l}\text { Mentha piperita L.var. } \\
\text { Citrata(Ehrh) Briq. }\end{array}$ & Lamiaceae & Yerba buena & Introducida & Tallo, hojas & Infusión & $\begin{array}{l}\text { Malestar del } \\
\text { estomago }\end{array}$ & $\begin{array}{l}\text { 005031 T. } \\
\text { Medina(1021) }\end{array}$ \\
\hline Mentha pulegium L. & Lamiaceae & Poleo & Introducida & $\begin{array}{l}\text { Toda la } \\
\text { planta }\end{array}$ & Decoción; oral & $\begin{array}{l}\text { Resfriados, } \\
\text { parasitos }\end{array}$ & $\begin{array}{l}\text { Confirmado } \\
\text { por expertos }\end{array}$ \\
\hline Monnina phytoiacaefolia H.B.K. & Polygalaceae & Ruchica & Nativa & Hoja & $\begin{array}{l}\text { Zumo, } \\
\text { uso interno }\end{array}$ & $\begin{array}{l}\text { Migraña y } \\
\text { sinocitis }\end{array}$ & $\begin{array}{l}009864 \\
\text { Ivan Camacho }\end{array}$ \\
\hline Muntingia calabura L. & Elaeocarpaceae & Chichato & Nativa & Hoja, flores & $\begin{array}{l}\text { Compresa, } \\
\text { uso externo }\end{array}$ & $\begin{array}{l}\text { Alivia los } \\
\text { brotes y granos }\end{array}$ & $\begin{array}{l}008661 \mathrm{G} . \\
\text { Dlaz(41) }\end{array}$ \\
\hline Murraya exotica L. & Myrtaceae & Mirto & Introducido & Hoja & Cataplasma & $\begin{array}{l}\text { Dolores } \\
\text { musculares }\end{array}$ & $\begin{array}{l}\text { O04247 D.D. } \\
\text { Soejarto y Mariela } \\
\text { de Soejarto }\end{array}$ \\
\hline $\begin{array}{l}\text { Myrsine guianensis } \\
\text { (Aublet) Kuntze. }\end{array}$ & Myrsinaceae & Cucharo & Nativa & Tallo & $\begin{array}{l}\text { Infusión, } \\
\text { uso externo }\end{array}$ & Riñones & $\begin{array}{l}009860 \\
\text { A. Torres (1) }\end{array}$ \\
\hline Ocimum basilicum L. & Lamiaceae & Albahaca & Introducida & $\begin{array}{l}\text { Toda la } \\
\text { planta }\end{array}$ & Cocimiento, oral & $\begin{array}{l}\text { Digestión, } \\
\text { golpes, } \\
\text { malestar } \\
\text { general }\end{array}$ & $\begin{array}{l}\text { 006986 Diana } \\
\text { Vlllanueva (3) }\end{array}$ \\
\hline Origanum majorana $\mathrm{L}$. & Lamiaceae & Mejorana & Introducida & $\begin{array}{l}\text { Toda la } \\
\text { planta }\end{array}$ & $\begin{array}{l}\text { Cocimiento, } \\
\text { uso interno }\end{array}$ & Bronquios & $\begin{array}{l}007516 \\
\text { Tulio García (5) }\end{array}$ \\
\hline Origanum vuigare L. & Lamiaceae & Oregano & Introducida & Hoja & $\begin{array}{l}\text { Infusión, } \\
\text { uso interno }\end{array}$ & Dolor de oido & $\begin{array}{l}\text { Confirmado } \\
\text { por expertos }\end{array}$ \\
\hline Piper peltatum L. & Piperaceae & Cordoncillo & Nativa & Hoja & $\begin{array}{l}\text { Infusión, } \\
\text { uso interno }\end{array}$ & $\begin{array}{l}\text { Dolencias } \\
\text { estomacales }\end{array}$ & $\begin{array}{l}407839 \text { Colector } \\
\text { H. E. Esquivel } \\
\text { (3494) }\end{array}$ \\
\hline Plantago major $\mathrm{L}$. & Plantaginaceae & Llantén & Naturalizada & Hojas & $\begin{array}{l}\text { Emplasto, } \\
\text { aplicación } \\
\text { externa }\end{array}$ & $\begin{array}{l}\text { Higado, vista, } \\
\text { picaduras, } \\
\text { heridas } \\
\text { abiertas, } \\
\text { Infecciones } \\
\text { estomacales }\end{array}$ & $\begin{array}{l}2076 \text { Jorge } \\
\text { Puente Acosta } \\
\text { (39) }\end{array}$ \\
\hline $\begin{array}{l}\text { Pseudelephantopus spicatus } \\
\text { (B. Juss. Ex Aubl.) C.F. Baker. }\end{array}$ & Asteraceae & $\begin{array}{l}\text { Hierba } \\
\text { de Golpe }\end{array}$ & Nativa & Hoja & $\begin{array}{l}\text { Cataplasma; uso } \\
\text { externo; infusión, } \\
\text { jarabe }\end{array}$ & $\begin{array}{l}\text { Dolencias } \\
\text { del higado }\end{array}$ & $\begin{array}{l}006685 \text { H. E. } \\
\text { Esquivel }(2353)\end{array}$ \\
\hline Psidium guineense SW. & Myrtaceae & $\begin{array}{l}\text { Guayabo } \\
\text { cimarron }\end{array}$ & Nativa & Hoja & Infusión, oral & $\begin{array}{l}\text { Colesterol, } \\
\text { Diabetes }\end{array}$ & $\begin{array}{l}008655 \text { Agudelo } \\
\text { Camacho (1) }\end{array}$ \\
\hline Rosmarinus officinalis. & Lamiaceae & Romero & Introducida & Hoja, flor & Cunguento & $\begin{array}{l}\text { Mejorar el } \\
\text { cabello }\end{array}$ & $\begin{array}{l}002461 \mathrm{R} . \\
\text { Echeverri }(2886)\end{array}$ \\
\hline Rumex crispus L. & Polygonaceae & $\begin{array}{l}\text { Rumasa o } \\
\text { Lengua de } \\
\text { vaca }\end{array}$ & Introducida & Raiz & $\begin{array}{l}\text { Infusión, } \\
\text { uso interno }\end{array}$ & $\begin{array}{l}\text { Afecciones } \\
\text { pulmonares }\end{array}$ & $\begin{array}{l}\text { 000330 R. } \\
\text { Echeverry (92) }\end{array}$ \\
\hline Ruta graveolens L. & Rutaceae & Ruda & Introducida & Hoja & Cocimiento, oral & Sacar frios & $\begin{array}{l}\text { O000122 Rafael } \\
\text { Cortez (61) }\end{array}$ \\
\hline Salvia palaefolia H.B.K. & Labiaceae & Mastranto & Nativa & $\begin{array}{l}\text { Toda la } \\
\text { planta }\end{array}$ & Cocimiento, oral & $\begin{array}{l}\text { Desvanecer } \\
\text { cuagulos }\end{array}$ & $\begin{array}{l}\text { 002360 R. } \\
\text { Echeverry (145) }\end{array}$ \\
\hline Sambucus nigra L. & Sambucaceae & Sauco & Introducida & $\begin{array}{l}\text { Toda la } \\
\text { planta }\end{array}$ & $\begin{array}{l}\text { Cocimiento, } \\
\text { uso Interno }\end{array}$ & Corazón & $\begin{array}{l}0000100 . \\
\text { Gutierrez (16) }\end{array}$ \\
\hline Smilax spp. & Liilaceae & Zarzaparrilla & Nativa & Raíz & Jarabe & $\begin{array}{l}\text { Purificar la } \\
\text { sangre, granos } \\
\text { infectados, } \\
\text { riñones }\end{array}$ & $\begin{array}{l}\text { Confirmado } \\
\text { por expertos }\end{array}$ \\
\hline
\end{tabular}




\begin{tabular}{|c|c|c|c|c|c|c|c|}
\hline Nombre Científico & Familia & $\begin{array}{l}\text { Nombre } \\
\text { Común }\end{array}$ & Origen & $\begin{array}{l}\text { Parte de } \\
\text { la Planta } \\
\text { utilizada }\end{array}$ & $\begin{array}{l}\text { Preparación } \\
\text { y modo de } \\
\text { administración }\end{array}$ & $\begin{array}{l}\text { Uso terapéutico } \\
\text { reportado por } \\
\text { los habitantes } \\
\text { de la cuenca }\end{array}$ & $\begin{array}{l}\text { Número de } \\
\text { Colección } \\
\text { Herbario UT }\end{array}$ \\
\hline Solanum americanum Mili. & Solanaceae & Hierba mora & Nativa & $\begin{array}{l}\text { Ramas, } \\
\text { hojas; Fruto }\end{array}$ & $\begin{array}{l}\text { Infusión, oral; } \\
\text { catplasma, } \\
\text { uso externo }\end{array}$ & $\begin{array}{l}\text { Calma el dolor } \\
\text { de muelas }\end{array}$ & $\begin{array}{l}007553 \text { M. } \\
\text { Rámirez y A. } \\
\text { Rámirez(158) }\end{array}$ \\
\hline $\begin{array}{l}\text { Taraxacum officinale. } \\
\text { Weber ex Winer. }\end{array}$ & Asteraceae & $\begin{array}{l}\text { Diente de } \\
\text { León }\end{array}$ & Naturalizada & $\begin{array}{l}\text { Toda la } \\
\text { planta }\end{array}$ & Cocimiento, oral & $\begin{array}{l}\text { Ulcera, Higado, } \\
\text { pulmones }\end{array}$ & $\begin{array}{l}7144 \mathrm{H} . \\
\text { Esquivel (2256) }\end{array}$ \\
\hline Trichanthera gigantea. & Acanthaceae & Cuchiyuyo & Nativa & Hojas & $\begin{array}{l}\text { cocimiento, } \\
\text { uso Interno }\end{array}$ & $\begin{array}{l}\text { Riñones y } \\
\text { limpia la } \\
\text { sangre }\end{array}$ & $\begin{array}{l}000736 \text { Ernesto } \\
\text { Otálora (62) }\end{array}$ \\
\hline Viola Odorata $L$. & Urticaceae & $\begin{array}{l}\text { Ortiga o } \\
\text { pringamosa }\end{array}$ & Naturalizada & Hojas, tallo & $\begin{array}{l}\text { Emplasto, } \\
\text { Aplicación } \\
\text { externa; } \\
\text { decocción, oral }\end{array}$ & $\begin{array}{l}\text { Labado de } \\
\text { heridas, } \\
\text { analgésico, } \\
\text { desinflamar, } \\
\text { purificar la } \\
\text { sangre, artritis }\end{array}$ & $\begin{array}{l}009401 \mathrm{H} . \mathrm{E} . \\
\text { Esquivel (6) }\end{array}$ \\
\hline Viola Odorata L. & Violaceae & Violeta & Introducida & Tallo, flor & Infusión, oral & Coilcos, fiebre & $\begin{array}{l}000173 \text { Ines } \\
\text { Troncoso (17) }\end{array}$ \\
\hline Xylopia aromatica (Lam) Mart. & Annonaceae & Sembe & Naturalizada & Hoja, fruto & $\begin{array}{l}\text { Infusión, uso } \\
\text { Interno }\end{array}$ & $\begin{array}{l}\text { Picaduras, } \\
\text { purificar la } \\
\text { sangre }\end{array}$ & $\begin{array}{l}005296 \mathrm{R} . \\
\text { Echeverry (4750) }\end{array}$ \\
\hline
\end{tabular}

Gráfica 1. Número de Familias Reportadas de plantas usadas con fines medicinales en la cuenca media y baja del Río Las Ceibas en Neiva, Huila, Colombia

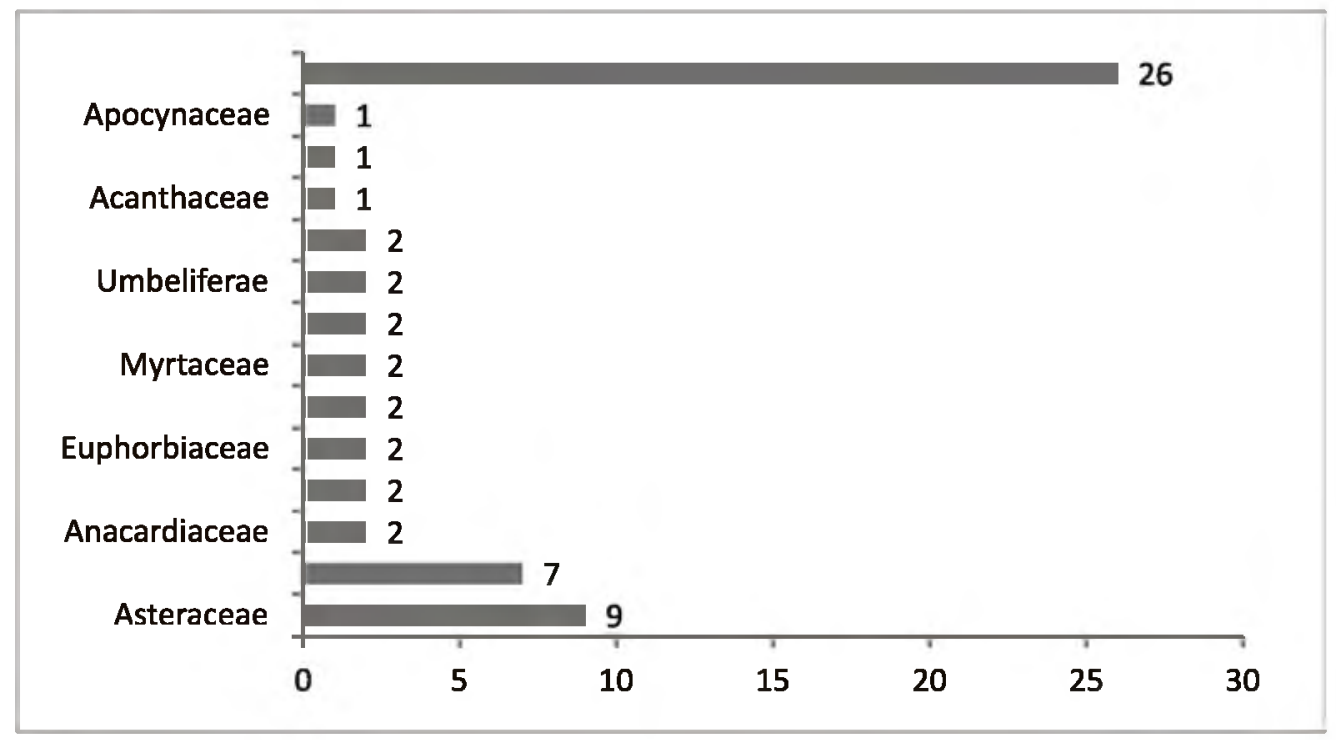

Los habitantes de la cuenca media y baja del río Las Ceibas usan con frecuencia las plantas medicinales para diversos fines que van desde la cura de enfermedades, la prevención de las mismas, hasta aspectos de carácter místico. De igual manera, se puede observar que el uso de estas plantas se debe a tradiciones familiares que trasmiten el conocimiento a la siguiente de generación; pero este conocimiento no le permite diferenciar entre las plantas nativas, las introducidas y las naturalizadas.

En este mismo orden de ideas, cabe señalar que las especies nativas a menudo son usadas para tratar diferentes infecciones y enfermedades con respecto a las de especies introducidas, pero hay algunas excepciones. Desde esta perspectiva, y en relación al Cuadro 1, es posible identificar la mayor prevalencia de las especies nativas que se citaron con tratamientos para enfermedades del sistema genitourinario, sistema nervioso, sistema digestivo, sistema endocrino, sistema circulatorio, sistema musculoesquelético, y otros trastornos de causa externa, como infecciosas, parásitos, enfermedades cutáneas. En cuanto a las plantas introducidas se citaron principalmente para el uso en el tratamiento de trastornos del sistema respiratorio, trastornos del sistema digestivo, trastornos del sistema nervioso y enfermedades del sistema circulatorio, para el 
tratamiento de desórdenes del sistema sensorial, trastornos místicos- religiosos, resfriados, antiinflamatorios y depurativos.

\section{Aplicación de criterios}

Seguidamente, se presenta la aplicación de criterios desarrollados según las metodologías propuestas por Cavero et al. (2010), Pérez (2006), CAM (2006), Martínez (2006), Marín-Corba et al. (2005) y Force et al. (1995).

Plantas Nativas: De las plantas identificadas por los habitantes de la cuenca media y baja del río Las Ceibas se seleccionaron las especies nativas, con el propósito de mantener la oferta ambiental de los bienes y servicios que se generan, y recuperar o mantener su estructura ecológica principal. Estableciendo este criterio se obtuvieron 30 especies nativas, 26 especies introducidas y 5 naturalizadas de las 61 especies vegetales de uso medicinal que identificaron los habitantes. Para avanzar en el proceso de selección del recurso forestal no maderable se descartaron las especies introducidas y naturalizadas, y se continuó aplicando los criterios a las 30 plantas nativas identificadas en el cuadro 1.
Plantas medicinales oficialmente aceptadas en Colombia: Después de determinar las 30 especies nativas que usan los habitantes de la cuenca media y baja del río Las Ceibas, el proceso de selección identificó que de éstas especies, el INVIMA permite en Colombia el uso terapéutico de 10 especies vegetales (cuadro 2).

Es necesario precisar que este aspecto se convierte en uno de los factores limitantes para plantear estrategias sostenibles para los recursos forestales no maderables con gran potencial para la incursión en estructuras de mercado a nivel nacional e internacional, tal es el caso del Croton gossypiifolius Vahl citado por los habitantes de la cuenca, el cual pertenece al mismo género y presenta propiedades medicinales similares al Croton lechleri Mull. Arg registrado en el vademécum, pero por no ser de la misma especie se restringe su comercialización.

En el vademécum Colombiano de plantas medicinales también se registra varias especies introducidas y naturalizadas mencionadas por los habitantes de la cuenca, pero estas especies vegetales con fines medicinales no fueron escogidas para continuar con el proceso, debido a que se pretende trabajar con la biodiversidad nativa como mecanismos de desarrollo sostenible en la cuenca.

Cuadro 2. Identificación de especies nativas presentes en la cuenca media y baja del río Las Ceibas que son aceptadas oficialmente en Colombia para usos medicinales.

\begin{tabular}{|l|l|}
\hline \multicolumn{2}{|c|}{ Nombre Científico } \\
\hline Bidens pilosa L. & Jacaranda caucana Pittier. \\
\hline Bixa orellana L. & Lippia alba (Mili.) N.E.Br. \\
\hline Cecropia peltata L. & Salvia palaefolia H.B.K. \\
\hline Curatella americana L. & Solanum americanum Mili. \\
\hline Eryngium foetidum L. & Gliricidia sepium (Jacq) Steud. \\
\hline
\end{tabular}

Frecuencia de citación, sumatoria de usos y valor de uso: Estos criterios se aplicaron a las 10 plantas nativas aceptadas para fines terapéuticos en Colombia por el Ministerio de la protección Social (Cuadro 2). La sumatoria de estos criterios permite asignar pesos acordes al uso que hace los habitantes, al potencial uso y a la aptitud que tiene la planta medicinal para satisfacer las necesidades terapéuticas de las personas que habitan la cuenca media y baja del río Las Ceibas (Cavero et al., 2010; Marín-Corba et al., 2005).

Dentro de la aplicación de estos criterios se observa que las plantas medicinales que tienen mayor frecuencia de citación en su orden de importancia son: el Matarratón, el Gualanday, la Hierba Mora, el Achiote y la Chipaca Pacunga (Cuadro 3).

La sumatoria de usos se realizó teniendo en cuenta los usos citados por los habitantes corroborados y complementados mediante revisión la bibliográfica, para determinar el uso potencial de cada planta. En este orden de ideas, se determinó que las plantas medicinales que tienen mayor potencial de uso son: el Pronto Alivio, la Chipaca Pacunga, el Cilantro Cimarrón, el Gualanday y el Achiote (Cuadro 3).

$\mathrm{Al}$ establecer el valor de uso se puede observar que los recursos forestales no maderables más valorados por los habitantes de la cuenca media y baja del río las Ceibas son: el Matarratón, Hierba Mora, Gualanday y Pronto Alivio y los menos valorados la Chipaca Pacunga, el Mastranto, el Cilantro Cimarrón, Achiote y el Yarumo (Cuadro 3). 
Cuadro 3. Asignación de pesos a las especies nativas según criterios de frecuencia de citación, sumatoria de usos y valor del uso.

\begin{tabular}{|l|c|c|c|}
\hline NOMBRE CIENTIFICO, FAMILIA BOTÁNICA & $\begin{array}{c}\text { FRECUENCIA } \\
\text { DE CITACIÓN }\end{array}$ & $\begin{array}{c}\text { SUMATORIA } \\
\text { DE USOS }\end{array}$ & VALOR DE USO \\
\hline Gliricidia sepium (Jacq) Steud. & 32 & 10 & 3,2 \\
\hline Lippia alba (MIII.) N.E.Br. & 24 & 19 & 1,3 \\
\hline Jacaranda caucana Pittier. & 27 & 15 & 1,8 \\
\hline Solanum nigrum L. & 26 & 11 & 2,4 \\
\hline Bidens pilosa L. & 18 & 19 & 0,9 \\
\hline Eryngium foetidumL. & 17 & 18 & 0,9 \\
\hline Bixa orellana L. & 12 & 14 & 0.9 \\
\hline SalviapalaefollaH.B.K. & 9 & 9 & 1,0 \\
\hline Curatella americana L. & 6 & 6 & 1,0 \\
\hline Cecropia peltata L. & 5 & 7 & 0,7 \\
\hline
\end{tabular}

Los pesos asignados en la sumatoria de criterios, generaron información más objetiva en cuanto al uso que hacen de los recursos seleccionados. En este orden de ideas, se observa que las 10 plantas hay un grupo de plantas más demandadas y representativas por los habitantes de la cuenca como son: Gliricidia sepium, Lippia alba, Jacaranda caucana, Solanum nigrum, Bidens pilosa, Eryngium foetidum y Bixa orellana; y otro grupo de plantas menos demandadas tales como: Salvia palaefolia, Curatella americana y Cecropia peltata (Gráfica 2).

Gráfica 2. Sumatoria de criterios para las especies nativas derivada de los pesos: frecuencia de citación, sumatoria de usos y valor del uso para las especies nativas.

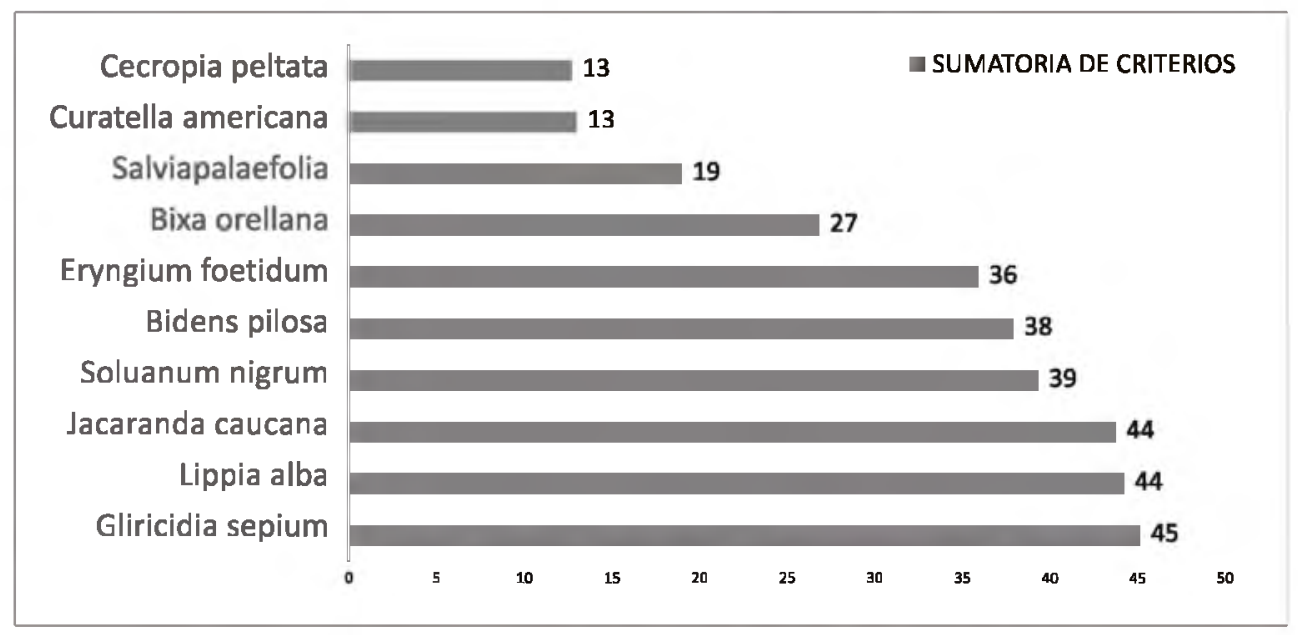

Demanda comercial y priorización en cadena productiva del sector: Para continuar con el proceso de selección del recurso forestal no maderable de la cuenca media y baja del río las ceibas, se aplicó el criterio de demanda comercial y priorización en la cadena productiva a las 10 plantas valoradas con el criterio anterior. Este criterio evaluó y analizó la dinámica comercial y la priorización que tienen cada una de estas plantas en las cadenas de comercialización. De esta manera, se logró seleccionar de las diez plantas medicinales la especie que contiene los valores más altos en las discreciones aplicadas.

De acuerdo con los resultados obtenidos de las entrevistas se pudo determinar que las plantas medicinales de mayor demanda comercial en la ciudad de Neiva, son plantas de clima frío y que provienen en especial de Cundinamarca, mientras que las plantas de menor comercialización y por ende menos demandadas por los habitantes de la ciudad de Neiva son especies que se dan de manera natural o se cultivan en la región norte del departamento del Huila.

Es importante señalar que Lippia alba presenta una demanda significativa a nivel nacional, sin embargo, su demanda en el comercio de las plantas medicinales en la ciudad de Neiva es muy bajo, situación que se presenta no por el poco uso de la planta, sino por el hecho de que la planta es muy común en la región.

La priorización de las 10 plantas medicinales dentro de la cadena productiva que se ha establecido a nivel nacional e internacional (Gráfica 3); según Díaz (2004) y el Departamento Nacional de Planeación (2003) las plantas de mayor demanda son Jacaranda caucana Pittier, Gliricidia sepium Jacq, Eryngium foetidum L. y Lippia alba Mill. N.E.Br; de igual manera PROEXPORT (2003) dentro de sus estadísticas menciona a Lippia 
alba Mill. N.E.Br, Bixa orellana L., Bidens pilosa L. y Salvia palaefolia H.B.K.; en este sentido, López et al. (2009) concuerdan en indicar a Jacaranda caucana Pittier y la Bixa orellana L. como las especies de mayor demanda. Cabe mencionar que la Cecropia peltata L., Curatella americana L. y la Solanum nigrum L. a pesar de ser representativas a nivel local, no se encuentran dentro de la estructura comercial del mercado de plantas medicinales, lo cual imposibilita la incursión de estas especies dentro de un sistema de comercialización.
Teniendo en cuenta el criterio de demanda comercial las plantas Curatella americana L., Cecropia peltata L., Gliricidia sepium Jacq, Solanum americanum Mill. y Eryngium foetidum L. son descartadas, puesto que su potencial comercial es muy bajo; seguidamente, al aplicar el criterio de priorización en la cadena productiva, las plantas Jacaranda caucana Pittier., Bidens pilosa L. y Salvia palaefolia H.B.K. pierden relevancia.

Gráfica 3. Asignación de pesos según demanda comercial, priorización en cadena productiva del sector y la sumatoria de estos dos criterios.

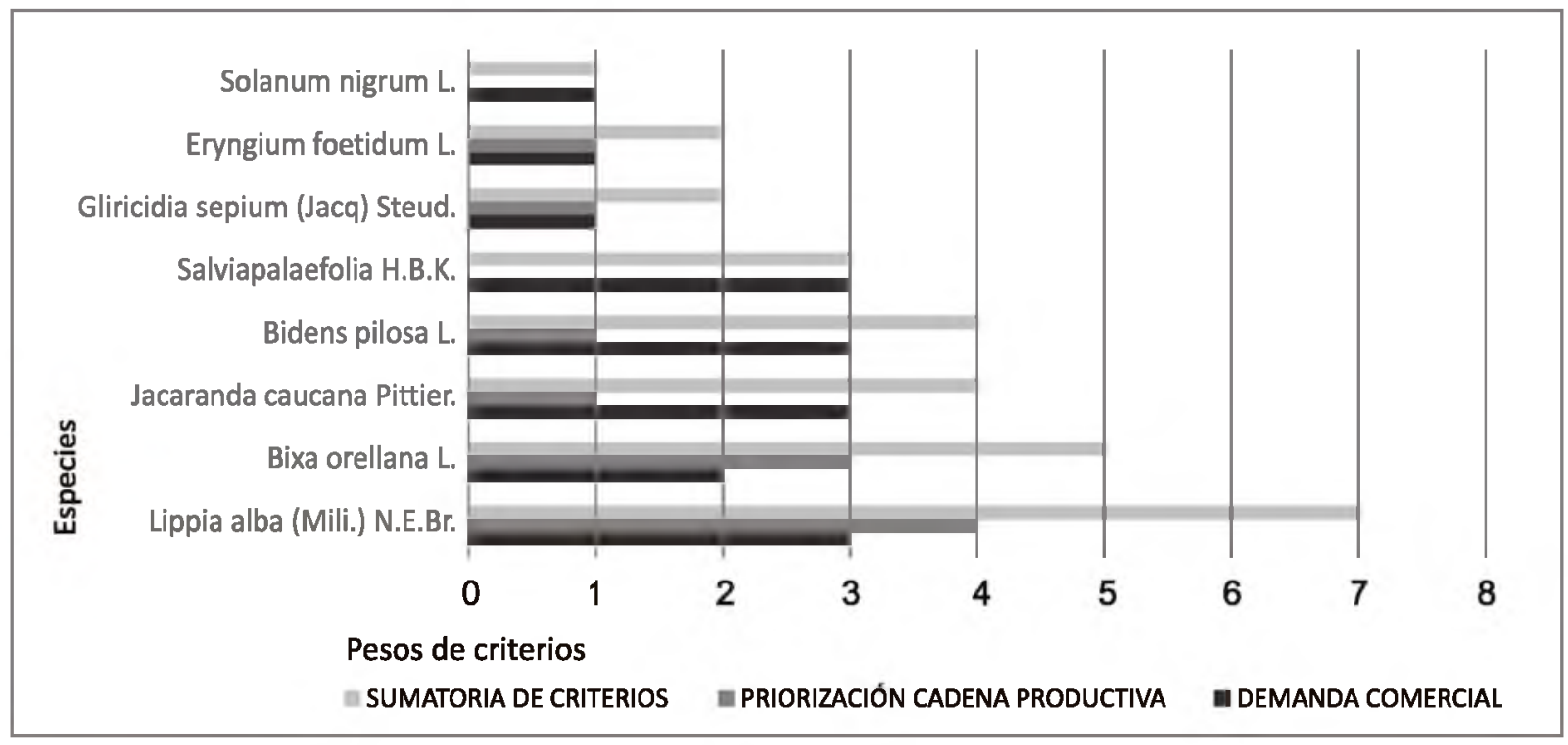

En consecuencia, con estos dos últimos criterios, las plantas seleccionadas en su orden de importancia de acuerdo al peso son: Lippia alba (Mill.) N.E.Br. y Bixa orellana L., pero es necesario aclarar que el Bixa orellana L. tiene gran demanda como colorante. Con referencia a lo anterior, la planta que posee un mayor potencial para el planteamiento de un aprovechamiento sostenible de un recurso forestal no maderable con fines medicinales en la cuenca media y baja del río Las Ceibas, con posibilidades reales de ingreso a la cadena productiva de las Plantas Aromáticas Medicinales y Condimentarías de Colombia es el Lippia alba (Mill.) N.E.Br. (Pronto Alivio), de la cual, sus extractos tienen una demanda comercial importante en los mercados nacionales e internacionales.

\section{Conclusiones y recomendaciones}

En la investigación se planteó la importancia de estudiar el recurso forestal no maderable del bosque con fines medicinales, para contribuir a la gestión integral de la cuenca del río Las Ceibas. Se emplearon metodologías de etnobotánica, de jerarquización y de economía. En consecuencia, se muestra que la integración de diferentes disciplinas permiten abordar problemáticas en la gestión de la cuenca del río Las
Ceibas; en especial cuando se trata de estudiar recursos naturales poco conocidos como es el caso de los recursos forestales no maderables.

De este modo, se logró identificar que las plantas: Bidens pilosa L. (Chipaca Pacunga), Bixa orellana L. (Achiote), Eryngium foetidum L. (Cilantro Cimarrón), Gliricidia sepium Jacq Steud (Matarratón), Jacaranda caucana Pittier (Gualanday), Lippia alba, Lippia citrodora L. (Cidrón), Solanum americanum Mill (Hierba Mora) y Salvia palaefolia H.B.K. (Mastranto) son las plantas medicinales con potencial para un posible aprovechamiento sostenible. En consecuencia, estas plantas se deben priorizar para futuras investigaciones y trabajos que pretendan el aprovechamiento sostenible de la cuenca y así contribuir a la conservación en la cuenca.

De las plantas anteriormente mencionadas y según las técnicas de identificación y jerarquización aplicadas, la especie Lippia alba es el recurso natural no forestal con fines medicinales que tiene las mejores oportunidades para establecer un sistema de aprovechamiento sostenible en la cuenca media y baja del río Las Ceibas que ingrese al mercado de las Plantas Aromáticas y Medicinales de Colombia. 
La información generada en esta investigación y los métodos aplicados para desarrollarla, contribuyen de manera importante al estudio del aprovechamiento de los recursos forestales no maderables en Colombia. De igual manera, se constituye en el primer avance en el departamento del Huila en cuanto al conocimiento referente al potencial de uso de los recursos biológicos; ya que no se queda sólo en la identificación y descripción del recurso potencial sino que expone una alternativa de gestión mediante el apoyo de disciplinas económicas aplicadas al biocomercio.

Los resultados muestran que la cuenca del río Las Ceibas, cuenta con una variedad de recursos biológicos latentes para incursionar en alternativas de desarrollo sostenible. En consecuencia, las oportunidades que brinda su biodiversidad, se constituyen en razones adicionales que aportan a lo estratégico del ecosistema en cuanto al ofrecimiento de bienes y servicios ambientales se refiere; lo cual desborda su importancia más allá del servicio hídrico para abastecer el acueducto de la ciudad de Neiva.

Es importante resaltar que el valor de uso, criterio empleado para la identificación del uso que hacen los habitantes de la cuenca media y baja del río Las Ceibas del recurso forestal no maderable, al expresar la demanda que existe por parte de ellos sobre ciertos recursos naturales, indica la posible presión que hay sobre las plantas Gliricidia sepium, Solanum americanum, Jacaranda caucana y Lippia alba. Por lo anteriormente expuesto, debe prestarse especial atención para establecer programas de manejo sostenible en posibles situaciones de extracción y así evitar su sobreexplotación.

\section{Referencias Bibliográficas}

Cavero, R. Y., Akerreta, S., y Calvo, M. I. (2011). Pharmaceutical ethnobotany in the Middle Navarra (Iberian Peninsula). Journal of Ethnopharmacology, 137(1), 844-855. doi:10.1016/j.jep.2011. 07. 001

COLOMBIA. CONGRESO DE LA REPÚBLICA DE COLOMBIA. Fundamentos de la política ambiental colombiana, Pub. L. No.99 (1993).

COLOMBIA. MINISTERIO DE LA PROTECCIÓN SOCIAL. Se reglamenta los regímenes de registro sanitarios, y vigilancia y control sanitario y publicidad de los productos fitoterapéuticos, Pub. L. No. Decreto 3553 (2004).

COLOMBIA. MINISTERIO DE LA PROTECCIÓN SOCIAL. (2004b) Vademécum Colombiano de Plantas Medicinales. Bogotá: Universidad Nacional de Colombia.

CONVENIO SOBRE LA DIVERSIDAD BIOLÓGICA. (2007). Examen a fondo de la aplicación del enfoque por ecosistemas (Ejecutivo No. UNEP/CBD/SBSTTA/12/2) (p. 15). Paris: UNEP, CDB. Retrieved from http://www.cbd.int/doc/meetings/sbstta/sbstta12/official/sbstta-12-02-es.pdf

CORPORACIÓN AUTÓNOMA REGIONAL DEL ALTO MAGDALENA. (2006). Plan de Ordenación y Manejo de la Cuenca Hidrográfica del río Las Ceibas. CAM.

DEPARTAMENTO NACIONAL DE PLANEACIÓN. (2003). Farmacéutica y medicamentos (pp. 361-367). Bogotá. Retrieved from https://www.dnp.gov.co/Portals/0/archivos/documentos/DDE/ Farmaceuticos.pdf

Díaz, J. (2003). Caracterización del mercado colombiano de plantas medicinales y aromáticas (p. 111). Bogotá: Instituto Alexander von Humboldt - El Ministerio de Ambiente Vivienda y Desarrollo Territorial.

Esquivel, H. (1992). Claves para la identificación de las especies arvenses de la familia asteraceae en el alto valle del río Magdalena (Colombia). Universidad Nacional de Colombia, Bogotá.
Esquivel, H. (2009). Flora arbórea de la ciudad de Ibagué. Ibagué: Corporación Autónoma Regional del Tolima.

Force, E., Machlis, G., Dalton, S., y Dalton, D. (1995). Monitoring social indicators for ecosystem management: The technical assessment data. Interior Columbia Basin Ecosystem Management Project. Retrieved from http://www.icbemp.gov/science/force.pdf

Galeano, G. (2000). Forest use at the pacific coast of chocó, Colombia: A quantitative approach. Economic Botany, 54(3), 358-376. doi:10.1007/BF02864787

Gómez, M. (2008). Estudio de mercado de productos forestales. Turrialba, C.R.: Centro Agronómico Tropical de Investigación y Enseñanza (CATIE). Retrieved from http://orton.catie.ac.cr/repdoc/A2695E/A2695E.PDF

Kammerbauer, J. (2001). Las dimensiones de la sostenibilidad: fundamentos ecológicos, modelos paradigmáticos y senderos. Interciencia. Retrieved June 18, 2010, from http://www.redalyc.org/resumen.oa?id=33905906

Kuehl, R. (2001). Diseño de experimentos: Principios estadísticos de diseño. México: University of Arizona.

López, L., Mejía, D., Gómez, J., y Albarracín, C (2009). Agenda prospectiva de investigación y desarrollo tecnológico para la cadena productiva de plantas medicinales, aromáticas, condimentarías y afines con énfasis en ingredientes naturales para la industria cosmética en Colombia. Bogotá: Ministerio de Agricultura y Desarrollo Territorio.

López, R., Navarro, J., Montero, M., Amaya, K., y Rodríguez, C. (2006). Manual de identificación de especies no maderables del corregimiento de Tarapacá, Colombia. Bogotá: Instituto Amazónico de Investigaciones Científicas (SINCHI), Cooperación Técnica Alemana GTZ.

Marín-Corba, C., Cárdenas-López, D., y Suárez-Suárez, S. (2005). Use Value usefulness in ethnobotany. Case study in Putumayo department (Colombia). Caldasia, 27(1), 89-101.

Martínez, G. (2005). Recolección y Comercialización de Plantas Medicinales en el Departamento Santa María, Provincia de Córdoba, Argentina. Journal Acta Farmacológica Bonaerense, 24(4), 575-584.

Martínez, R. (2006). Elementos conceptuales que apoyan las decisiones sobre el fomento de productos forestales no maderables (Ensayo) (p. 15). Bogota: University of Queesland. Retrieved from http://www.banrepcultural.org/sites/default/ files/elementos-conceptuales.pdf

Maya, C., y Agudelo, C. (2010). Lista anotada de las especies de Euporbiaceae para el Quindío. Revista Investigaciones Universidad Del Quindío, 20, 126-136.

Mejías, C. R. (2002). Indicadores de sostenibilidad ambiental. Observatorio Medioambiental, 5, 79-99. doi:-

Olaya, A. (2003). Los ecosistemas estratégicos del Huila según su reconocimiento legal y su área de influencia. In Ecosistemas Estratégicos del Huila: Significado ecológico y cultural (pp. 155182). Neiva: Universidad Surcolombiana.

Olaya, A. (2005). Significado ecológico y sociocultural de los ecosistemas estratégicos del Huila y la región Surcolombiana, un proyecto en curso. In La USCO piensa la región: aportes desde la investigación. Neiva: Universidad Surcolombiana.

Olaya, A., y Sánchez, M. (Eds.). (2003). Ecosistemas estratégicos del Huila: Significado ecológico y sociocultural (1st ed.). Neiva: Universidad Surcolombiana.

Patiño, A. (2004). Jerarquización y descripción de los ecosistemas estratégicos de la subregión norte del Huila según criterios ecológicos y socioculturales. Surcolombiana, Neiva.

Perafan, J. (2009). Inventario de plantas medicinales de alta demanda utilizados con fines terapeuticos, en los municipios de Neiva y Palermo (p. 61). Neiva: UNAD.

Pérez, E. (1994). Plantas útiles de Colombia: Tercera redacción muy corregida y aumentada (14th ed.). Medellín: DAMA, Fondo FEN Colombia, Jardín Botánico José Celestino Mutis.

PROEXPORT. (2003). Estudio de oferta y demanda del sector de productos naturales. Bogotá: PROEXPORT.

Puelles, M. (2008). Estudio de la viabilidad comercial de plantas medicinales en zonas rurales altas del Valle del Mantaro (Perú) (Resumen de resultados y conclusiones) (pp. 2-10). Madrid: Universidad de Complutense.

Retrieved from http://www.reduniversitaria.es/investigacion/Plantas Medicinales-res.pdf

Romero, M. E. M. de, Martínez, S., Atkins, S., y Rotman, A. D. (2002). Morfología de las inflorescencias en Verbenaceae-Verbenoideae III. Tribe Lantaneae p.p. Darwiniana. Retrieved June 20, 2014, from http://www.redalyc.org/resumen.oa?id=66940401

Sanso, A. M., Xifreda, C. C., y Colasante, M. (2005). Especies de Viola (Violaceae) adventicias en Argentina. Darwiniana, 43(1-4), 192-200. 
SECRETARÍA DEL CONVENIO SOBRE LA DIVERSIDAD BIOLÓGICA. (2004). Enfoque por ecosistemas. Montreal: PNUMA, CDB. Retrieved from https://www.cbd.int/doc/publications/ea-textes.pdf

Silva, T. R. dos S., y Salimena, F. R. G. (2002). Novas combinacoes e novos sinonimos em Lippia e Lantana (Verbenaceae). Darwiniana, 40(1-4), 57-59.

Vega, M. (2001). Etobotánica de la Amazonía Peruana. Quito: AbyaYala. Retrieved from

http://repository.unm.edu/bitstream/handle/1928/11667/Etno bot\%C3\%A1nica\%20de\%20la\%20amazon\%C3\%ADa\%20peruana.pd

f?sequence $=1$ 